\title{
Ovarian function and ovarian blood supply following premenopausal abdominal hysterectomy
}

\author{
Ibrahim A. Abdelazim ${ }^{1,2}$, Khaled M. Abdelrazak ${ }^{1}$, Assem A.M. Elbiaa ${ }^{1,3}$, Mohamed M. Farghali ${ }^{1}$, \\ Amr Essam ${ }^{1}$, Gulmira Zhurabekova ${ }^{4}$ \\ ${ }^{1}$ Ain Shams University, Cairo, Egypt \\ ${ }^{2}$ Ahmadi Kuwait Oil (KOC) Company Hospital, Kuwait \\ ${ }^{3}$ Sabah Maternity Hospital, Kuwait \\ ${ }^{4}$ Department of Normal and Topographical Anatomy, Marat Ospanov, West Kazakhstan State Medical University, Kazakhstan
}

\begin{abstract}
Introduction: The issue of conserving the ovaries at hysterectomy in premenopausal women with benign gynecologic disease has been the subject of considerable controversy. Some clinicians prefer prophylactic oophorectomy in premenopausal women during hysterectomy to prevent future development of malignant changes in conserved ovaries. Other clinicians prefer to conserve apparently normal ovaries, because bilateral oophorectomy in premenopausal women results in an abrupt imbalance, sudden onset of menopausal symptoms, decreased libido, increased cardiovascular risk and osteoporosis.

Material and methods: Two hundred and twenty multipara women (who had completed their families), with benign uterine pathology were included in this prospective study for abdominal hysterectomy with bilateral ovarian preservation. Pre-operative vaginal ultrasound, Doppler studies, diagnostic hysteroscopy and endometrial biopsy were done followed by laboratory studies including Anti-mullerian hormone (AMH), follicle stimulating hormone (FSH) and estradiol for all studied women. Doppler studies, AMH, FSH and estradiol were repeated 6 and 12 months post-operative for assessment of the ovarian function and ovarian blood supply after hysterectomy.

Results: Pre-operative AMH, FSH and estradiol of the studied women were statistically insignificant compared to AMH, FSH and estradiol 6 and 12 months post-operative. Twelve months post-operative right and left ovarian volumes (6.92 \pm 0.18 and $6.85 \pm 0.19 \mathrm{~cm}^{3}$, respectively) were significantly larger than pre-operative right and left ovarian volumes ( $6.19 \pm 0.22$ and $5.86 \pm 0.23 \mathrm{~cm}^{3}$, respectively), and, 12 months post-operative right and left ovarian pulsatility indices $(2.92 \pm 0.15$ and $2.96 \pm 0.16 \mathrm{~cm} / \mathrm{s}$, respectively) were significantly lower than pre-operative right and left ovarian pulsatility indices ( $3.45 \pm 0.19$ and $3.36 \pm 0.2 \mathrm{~cm} / \mathrm{s}$, respectively). Eight (3.6\%) cases of the studied women developed an ovarian cyst 6 months after hysterectomy, 3 were spontaneously resolved and the remaining 5 (2.27\%) cases underwent exploratory laparotomy.

Conclusions: There is no evidence of ovarian dysfunction affecting conserved ovaries one year after hysterectomy in premenopausal women as evident by AMH, FSH and estradiol. Furthermore, an increased ovarian volume and reduced ovarian pulsatility indices indicate a possible increase in ovarian blood supply, and preserved non-compromised ovarian function.
\end{abstract}

Key words: ovarian, function, blood supply, premenopausal, abdominal hysterectomy.

\section{Introduction}

The issue of conserving the ovaries at hysterectomy in premenopausal women with benign gynecologic disease has been the subject of considerable controversy [1-5]. Some clinicians prefer prophylactic oophorectomy in premenopausal women during hysterectomy to prevent future development of malignant changes in conserved ovaries [6-16].

Other clinicians prefer to conserve apparently normal ovaries, because bilateral oophorectomy in premen- opausal women results in an abrupt imbalance, sudden onset of menopausal symptoms, decreased libido, increased cardiovascular risk and osteoporosis [17-23].

There is conflicting evidence regarding the effect of premenopausal hysterectomy on the conserved ovarian function. Some research indicates an increase in incidence and severity of menopausal symptoms following removal of the uterus despite the ovaries remaining in place, which may be due to reduction in ovarian blood flow and follicular atresia [6]. Animal studies (rat models) concluded that hysterectomy with ovarian conser- 
vation could preserve a normal hormonal milieu but might accelerate the onset of early menopause [24, 25]. This prospective study was designed to detect the effect of premenopausal abdominal hysterectomy on the ovarian function and ovarian blood supply.

\section{Material and methods}

Two hundred and twenty (220) women with benign uterine pathology were included in this study for abdominal hysterectomy with bilateral ovarian preservation which was conducted in Ahmadi, Kuwait Oil Company (KOC) and Sabah Maternity Hospitals, Kuwait, from January 2012 to January 2014. Women included in this study were 38-45 years old, multipara (had completed their families), with benign uterine pathology. Women planning future pregnancy or with other gynecological problems indicating alternative surgery such as endometriosis or cervical intraepithelial neoplasia (CIN) or ovarian masses were excluded from this study and women who had one or both ovaries removed in a previous surgery or malignant pelvic pathology or follicle stimulating hormone (FSH) of more than $20 \mathrm{IU} / \mathrm{ml}$ (on at least two sessions) were also excluded from this study. Women were included in this study after informed consent, proper counseling and approval of the study protocol by the institute's ethics committee. After complete history, physical examination, preoperative vaginal ultrasound, Doppler studies, diagnostic hysteroscopy and endometrial biopsy were done for all studied women, followed by pre-operative laboratory studies including Anti-mullerian hormone $(\mathrm{AMH}), \mathrm{FSH}$ and estradiol. Doppler studies, AMH, FSH and estradiol were repeated 6 and 12 months postoperative for assessment of the ovarian function and blood supply after abdominal hysterectomy. Blood samples were collected from women included in this study pre-operative, 6 and 12 months after hysterectomy in plain tubes, centrifuged and serum samples were stored at $-20^{\circ} \mathrm{C}$. AMH, FSH and estradiol levels in serum were measured by electrochemiluminescence immunoassay (ECLIA) using Elecsys Kits (Roche Diagnostics, Mannheim, Germany). Ovarian volume was measured in the pelvic infundibulum by transvaginal ultrasound and Doppler ultrasonography was used to assess the ovarian flow velocity waveform by measuring the Pulsatility Index (PI; cm/s) pre-operative, and 6 and 12 months after hysterectomy. All examinations were conducted during the follicular phase of the menstrual cycle by the same investigator, in the afternoon. In hysterectomized women, the follicular phase was determined by the absence of both a dominant follicle and corpus luteum [18]. Doppler ultrasonography of the ovarian arteries was done at the follicular phase of the menstrual cycle because flow is reduced and similar in both ovaries during this period [18].
Transvaginal ultrasound and Doppler studies were done using Philips HD9 (Philips International; Amsterdam; Netherlands) with a two-dimensional endo-vaginal convex probe 4-9 $\mathrm{MHz}$ by a sonographer who was blinded to the patients' criteria.

Baseline measures included transverse (T), anteroposterior (AP), and longitudinal (L) diameters of both ovaries and ovarian volume $(\mathrm{V})$, was estimated using the formula $V(\mathrm{~cm})=\mathrm{T}(\mathrm{Cm}) \times A P(\mathrm{Cm}) \times \mathrm{L}(\mathrm{Cm}) \times 0.52$. Left and right ovarian artery flow in the pelvic infundibulum was visualized with the color Doppler technique and the typical velocity spectrum of this vessel was determined. Blood flow impedance was expressed as the $\mathrm{PI}(\mathrm{cm} / \mathrm{s})$. The PI values were calculated electronically according to the formula $\mathrm{PI}=$ peak systolic velocity minimum diastolic velocity/mean flow velocity.

\section{Sample size justification}

The required sample size was calculated using $G^{*}$ Power software version 3.17 for sample size calculation ( ${ }^{\star}$ Heinrich Heine Universität, Düsseldorf, Germany), setting $\alpha$-error probability at 0.05 , power $(1-\beta$ error probability) at $0.95 \%$ and effective sample size $(w)$ at 0.3 . The effective size $(w)$ was calculated as follows: $w=\sqrt{\chi^{2} / N}$, where $\chi^{2}$ is the chi-square test and $N$ is the total sample size. The number of participants needed to produce a statistically acceptable figure was 220 women.

\section{Statistical analysis}

Data were collected, tabulated, then statistically analyzed using the Statistical Package for Social Sciences (SPSS) computer software version 18. Numerical variables were presented as mean and standard deviation ( \pm SD), while categorical variables were presented as a number and percentage. Student $t$-test was used for comparison between groups as regards quantitative variables. A difference with a $p$ value $<0.05$ was considered statistically significant.

\section{Results}

Mean age of premenopausal women included in this study for hysterectomy was $42.3 \pm 8.7$ years, parity was $4.9 \pm 1.6$ and body mass index (BMI) was $32.1 \pm 2.07$ $\mathrm{kg} / \mathrm{m}^{2}$. Hysterectomy was indicated for studied women due to fibroid uterus 131 (59.6\%) cases (causing pelvic-abdominal mass 51 [23.2\%] cases, menorrhagia 47 [21.4\%] cases, pelvic pain or pressure 33 [15\%] cases), heavy menstrual bleeding (HMB) with failed medical and hormonal treatment $52(23.6 \%)$ cases and polymenorrhea 37 (16.8\%) cases. The pre-operative histology of endometrium samples showed secretory endometrium in 87 (39.5\%) cases, proliferative endometrium in 
Tab. I. Indications of hysterectomy for the studied population and preoperative histology of endometrial samples

\begin{tabular}{|c|c|}
\hline Variables & Number (\%) \\
\hline \multicolumn{2}{|l|}{ Indication of hysterectomy } \\
\hline Fibroid uterus & $131(59.6 \%)$ \\
\hline Pelvic-abdominal mass & $51(23.2 \%)$ \\
\hline Menorrhagia & $47(21.4 \%)$ \\
\hline Pelvic pain or pressure symptoms & $33(15 \%)$ \\
\hline Heavy menstrual bleeding (HMB) & $52(23.6 \%)$ \\
\hline Polymenorrhea & $37(16.8 \%)$ \\
\hline \multicolumn{2}{|c|}{ Pre-operative histology of endometrium samples } \\
\hline Secretary endometrium & 87 (39.5\%) \\
\hline Proliferative endometrium & 69 (31.4\%) \\
\hline Simple hyperplasia & $36(16.4 \%)$ \\
\hline Complex hyperplasia without atypia & $28(12.7 \%)$ \\
\hline
\end{tabular}

69 (31.4\%) cases, simple endometrial hyperplasia in 36 (16.4\%) cases and complex hyperplasia without atypia in $28(12.7 \%)$ cases (Table I).

Pre-operative AMH $(1.75 \pm 4.61 \mathrm{ng} / \mathrm{ml})$ of the studied women was statistically insignificant compared to $\mathrm{AMH}$ 6 and 12 months post-operative $(1.78 \pm 2.45$ and $1.81 \pm$ $2.19 \mathrm{ng} / \mathrm{ml}$, respectively) and pre-operative FSH (7.98 \pm $5.7 \mathrm{IU} / \mathrm{ml}$ ) was statistically insignificant compared to FSH 6 and 12 months post-operative $(8.26 \pm 5.4$ and $8.55 \pm$ $6.2 \mathrm{lU} / \mathrm{ml}$, respectively), also, pre-operative estradiol (129 $\pm 57.3 \mathrm{pg} / \mathrm{ml}$ ) was statistically insignificant compared to estradiol 6 and 12 months post-operative (134.5 \pm 66.2 and $139.3 \pm 77.1 \mathrm{pg} / \mathrm{ml}$, respectively) (Table II).
Pre-operative right and left ovarian volumes (6.19 \pm 0.22 and $5.86 \pm 0.23 \mathrm{~cm}^{3}$, respectively) were statistically insignificant compared to 6 months post-operative right and left ovarian volumes $(6.75 \pm 0.25$ and $6.57 \pm$ $1.12 \mathrm{~cm}^{3}$, respectively), and were significantly smaller compared to 12 months post-operative right and left ovarian volumes $\left(6.92 \pm 0.18\right.$ and $6.85 \pm 0.19 \mathrm{~cm}^{3}$, respectively) (Table II).

Pre-operative right and left ovarian pulsatility indices ( $3.45 \pm 0.19$ and $3.36 \pm 0.2 \mathrm{~cm} / \mathrm{s}$, respectively) were statistically insignificant compared to 6 months post-operative right and left ovarian pulsatility indices (3.12 \pm 0.21 and $3.07 \pm 0.21 \mathrm{~cm} / \mathrm{s}$, respectively), and were significantly higher compared to 12 months post-operative right and left ovary pulsatility indices (2.92 \pm 0.15 and $2.96 \pm$ $0.16 \mathrm{~cm} / \mathrm{s}$, respectively) (Table II).

Eight (3.6\%) cases of the studied women developed an ovarian cyst 6 months after hysterectomy, 3 were spontaneously resolved and the remaining 5 (2.27\%) cases underwent exploratory laparotomy which revealed 3 cases of serous cystadenoma and 2 cases of a paraovarian cyst.

\section{Discussion}

In this study, there is no evidence of ovarian dysfunction affecting conserved ovaries one year after abdominal hysterectomy in premenopausal women as evident by $\mathrm{AMH}, \mathrm{FSH}$ and estradiol.

There is conflicting evidence regarding the effect of premenopausal hysterectomy on the ovarian function. Some research indicates an increase in incidence and severity of menopausal symptoms and ovarian failure following removal of the uterus, despite the ovaries

Tab. II. Preoperative and postoperative Anti-mullerian hormone (AMH), follicle stimulating hormone (FSH), estradiol, ovarian volume, ovarian Pulsatility Index (PI) of the studied population

\begin{tabular}{|c|c|c|c|c|}
\hline Variables & Preoperative & $\begin{array}{l}6 \text { months } \\
\text { postoperative }\end{array}$ & $\begin{array}{l}12 \text { months } \\
\text { postoperative }\end{array}$ & $P$ value $(95 \% \mathrm{Cl})$ test used \\
\hline $\mathrm{AMH}(\mathrm{ng} / \mathrm{ml})$, mean $\pm \mathrm{SD}$ & $1.75 \pm 4.61$ & $1.78 \pm 2.45$ & $1.81 \pm 2.19$ & $\begin{array}{l}\mathrm{P} 1=0^{\star *}(\mathrm{Cl}:-0.71 ;-0.03 ; 0.65), t \text { test } \\
\mathrm{P} 2=0^{\star *}(\mathrm{Cl}:-0.73 ;-0.06 ; 0.61), t \text { test }\end{array}$ \\
\hline $\mathrm{FSH}(\mathrm{IU} / \mathrm{ml})$, mean $\pm \mathrm{SD}$ & $7.98 \pm 5.7$ & $8.26 \pm 5.4$ & $8.55 \pm 6.2$ & $\begin{array}{l}\mathrm{P} 1=0.21^{* *}(\mathrm{Cl}:-1.31 ;-0.28 ; 0.75), t \text { test } \\
\mathrm{P} 2=0.89^{* *}(\mathrm{Cl}:-1.68 ;-0.57 ; 0.54), t \text { test }\end{array}$ \\
\hline Estradiol $(\mathrm{pg} / \mathrm{ml})$, mean $\pm \mathrm{SD}$ & $129.0 \pm 57.3$ & $134.5 \pm 66.2$ & $139.3 \pm 77.1$ & $\begin{array}{l}\mathrm{P} 1=0.98^{* *}(\mathrm{Cl}:-17.0 ;-5.5 ; 0.06), t \text { test } \\
\mathrm{P} 2=0.99^{* *}(\mathrm{Cl}:-22.9 ;-10.3 ; 2.39), t \text { test }\end{array}$ \\
\hline $\begin{array}{l}\text { Right ovarian volume }\left(\mathrm{cm}^{3}\right) \\
\text { mean } \pm \mathrm{SD}\end{array}$ & $6.19 \pm 0.22$ & $6.75 \pm 0.25$ & $6.92 \pm 0.18$ & $\begin{array}{l}\mathrm{P} 1=0.97^{* *}(-0.60 ;-0.56 ;-0.51), t \text { test } \\
\mathrm{P} 2=0.001^{\star}(-0.82 ;-0.79 ;-0.75), t \text { test }\end{array}$ \\
\hline $\begin{array}{l}\text { Left ovarian volume }\left(\mathrm{cm}^{3}\right) \\
\text { mean } \pm \mathrm{SD}\end{array}$ & $5.86 \pm 0.23$ & $6.57 \pm 1.12$ & $6.85 \pm 0.19$ & $\begin{array}{c}\mathrm{P} 1=1^{* *}(-0.86 ;-0.71 ;-0.55), t \text { test } \\
\mathrm{P} 2=0.002^{*}(-1.02 ;-0.99 ;-0.95), t \text { test }\end{array}$ \\
\hline $\begin{array}{l}\text { Right ovary Pulsatility Index } \\
(\mathrm{cm} / \mathrm{s}) \text {, mean } \pm \mathrm{SD}\end{array}$ & $3.45 \pm 0.19$ & $3.12 \pm 0.21$ & $2.92 \pm 0.15$ & $\begin{array}{c}P 1=0.9^{* *}(0.29 ; 0.33 ; 0.36), t \text { test } \\
P 2=0.002^{*}(0.48 ; 0.53 ; 0.56), t \text { test }\end{array}$ \\
\hline $\begin{array}{l}\text { Left ovary Pulsatility Index } \\
(\mathrm{cm} / \mathrm{s}) \text {, mean } \pm \text { SD }\end{array}$ & $3.36 \pm 0.2$ & $3.07 \pm 0.21$ & $2.96 \pm 0.16$ & $\begin{array}{c}P 1=0.9^{* *}(0.25 ; 0.2 ; 0.32), t \text { test } \\
P 2=0.0005^{*}(0.36 ; 0.4 ; 0.43), t \text { test }\end{array}$ \\
\hline
\end{tabular}

**Non-significant, *Significant

P1 - $p$ for preoperative values compared to 6 months postoperative values, P2 - $p$ for preoperative values compared to 12 months postoperative values, $t$ test - Student $t$-test, $\mathrm{cm} / \mathrm{s}-\mathrm{cm} /$ second 
remaining in place [26], whereas others report no decrease in ovarian function [26].

The advance of menopause age after hysterectomy is related to an increased rate of follicular atresia (surgical removal of uterus will increase follicular atresia in conserved ovaries) [27]. The presence of uterus would inhibit follicle depletion or atresia and its surgical removal at reproductive age would accelerate follicular loss, atresia and subsequent accelerated menopause [27].

Other hypothesis, the increased prevalence of ovarian failure after hysterectomy, is due to stretch and thrombosis of ovarian blood vessels with a subsequent reduction in ovarian blood supply $[17,27,28]$.

Deng et al. concluded that hysterectomy with the conservation of bilateral/unilateral ovaries may have some influence on the ovarian function [17], also, Ahn et al. concluded that total abdominal hysterectomy accelerates ovarian dysfunction and women treated with total abdominal hysterectomy are at risk of early menopause [6].

On the contrary, Ylikorkala and Viinikka studied pituitary-ovarian function in 2 women with congenital absence of the uterus and vagina (Mayer-Rokitansky-Kuster-Hauser syndrome) and concluded that presence or absence of the uterus does not affect the ovarian function [29].

In this study, pre-operative $\mathrm{AMH}, \mathrm{FSH}$ and estradiol were statistically insignificant compared to $\mathrm{AMH}, \mathrm{FSH}$ and estradiol 6 and 12 months after abdominal hysterectomy, also, Chalmers et al., concluded that there is no evidence of compromise of the ovarian function, as reflected in FSH levels, within 2 years of hysterectomy [19].

Findley et al. concluded that laparoscopic hysterectomy \pm salpingectomy with ovarian preservation does not appear to have any short-term deleterious effects on ovarian reserve, as measured by the $\mathrm{AMH}$ level [30].

Morelli et al. compared women treated with total laparoscopic hysterectomy (TLH) plus bilateral salpingectomy, with women treated by TLH without adnexectomy and they found no significant difference between two groups regarding $\mathrm{AMH}, \mathrm{FSH}$, antral follicle count (AFC), mean ovarian diameters and peak systolic velocity [31].

Recently, Venturella et al. has concluded that OvAge is one of the first reliable attempts to create a new method able to identify ovarian reserve $[32,33]$.

Although, Ishii et al. found that fifteen of $33 \mathrm{pa}$ tients became climacteric after premenopausal radical hysterectomy for stage IB and II cervical cancer with ovarian preservation, they also found a significant correlation between ovarian dysfunction after radical hysterectomy and age [34]. Petri Nahás et al. found that ovarian volumes were greater 6 and 12 months after total abdominal hysterectomy compared to controls and they found reduced $\mathrm{Pl}$ of ovarian vessels of hysterectomized women compared to controls [18].
They concluded that the reduced PI of ovarian vessels of hysterectomized women indicates decreased resistance with a subsequent increased ovarian blood flow in hysterectomized women compared to controls, also, in this study, 12 months post-operative right and left ovarian volumes $\left(6.92 \pm 0.18\right.$ and $6.85 \pm 0.19 \mathrm{~cm}^{3}$, respectively) were significantly larger than pre-operative right and left ovarian volumes $(6.19 \pm 0.22$ and $5.86 \pm$ $0.23 \mathrm{~cm}^{3}$, respectively), and, 12 months post-operative right and left ovary pulsatility indices $(2.92 \pm 0.15$ and $2.96 \pm 0.16 \mathrm{~cm} / \mathrm{s}$, respectively) were significantly lower than pre-operative right and left ovarian pulsatility indices (3.45 \pm 0.19 and $3.36 \pm 0.2 \mathrm{~cm} / \mathrm{s}$, respectively) [18]

Five to eight percent of hysterectomized women require subsequent surgeries for benign ovarian diseases [5]. The post-hysterectomy ovarian cysts appear within the first post-operative year and spontaneously resolved in more than $50 \%$ of cases, and most of these cysts are functional cysts [35]. Zalel et al. found ovarian cysts in $50.7 \%$ of hysterectomized women (37/73) and Pete et al. found ovarian cysts in $9.2 \%$ of hysterectomized women $(6 / 65)$ [36, 37].

Four women were lost during follow up (excluded from the study) and short duration of post-operative follow up (one year) were the two limitations faced during this study.

\section{Conclusions}

There is no evidence of ovarian dysfunction affecting conserved ovaries one year after hysterectomy in premenopausal women as evident by $\mathrm{AMH}, \mathrm{FSH}$ and estradiol. Furthermore, an increased ovarian volume and reduced ovarian $\mathrm{PI}$ indicates a possible increase in ovarian blood supply, and preserved, non-compromised ovarian function.

\section{Acknowledgement}

Authors are very grateful to women who agreed to participate in this study.

\section{Disclosure}

Authors declare no conflict of interest.

\section{References}

1. Yavuzcan A, Yıldız G, Çağlar M, et al. Which one is safer - performing a laparoscopic hysterectomy with a tissue fusion device involving diagnostic cystoscopy or traditional abdominal hysterectomy with ureteral dissection? Videosurgery Miniinv 2013; 8: 280-288.

2. Grabowski A, Korlacki W, Pasierbek M. Laparoscopy in elective and emergency management of ovarian pathology in children and adolescents. Videosurgery Miniinv 2014; 9: 164-169.

3. Wilczyński M, Cieślak J, Malinowski A. Supracervical hysterectomy - the vaginal route. Videosurgery Miniinv 2014; 9: 207-212. 
4. Ceccaroni M, Roviglione G, Pesci A, et al. Total laparoscopic hysterectomy of very enlarged uterus (3030 g): case report and review of the literature. Videosurgery Miniinv 2014; 9: 302-307.

5. Reich H. Issues surrounding surgical menopause. Indications and procedures. J Reprod Med 2001; 46 (3 Suppl): 297-306.

6. Ahn EH, Bai SW, Song $\mathrm{CH}$, et al. Effect of premenopausal hysterectomy on ovarian function. Yoseni Med J 2002; 43: 53-58.

7. Rogala E, Nowicka A, Bednarek W, et al. Evaluation of the expression of the immunosuppressive enzyme - indoleamine 2,3-dioxygenase in ovarian cancer tissue. Prz Menopauzalny 2013; 17: 223-227.

8. Gottwald L, Danilewicz M, Fendler W, et al. The AgNORs count in predicting long-term survival in serous ovarian cancer. Arch Med Sci 2014; 10: 84-90

9. Moulla A, Miliaras D, Sioga A, et al. The immunohistochemical expression of CD24 and CD171 adhesion molecules in borderline ovarian tumors. Pol J Pathol 2013; 64: 180-184.

10. Denel M, Marczak A. Panels of protein biomarkers and non-protein markers in the diagnosis of the ovarian cancer. Prz Menopauzalny 2013; 17: 404-408.

11. Tkaczuk-Włach J, Sobstyl M, Jakiel G. Biochemical markers for screening of ovarian cancer. Prz Menopauzalny 2013; 17: 442-445.

12. Smolarz B, Makowska M, Samulak D, et al. Association between polymorphisms of the DNA repair gene. RAD51 and ovarian cancer. Pol J Pathol 2013; 64: 290-295.

13. Lipińska N, Rubiś B. Telomerase as a target in diagnosis and treatment of cancer in postmenopausal women. Prz Menopauzalny 2013; 17: 478-483.

14. Marczak A, Bukowska B. New trends in the ovarian cancer treatment. Prz Menopauzalny 2013; 17: 489-492.

15. Dębska-Szmich S, Czernek U, Krakowska M, et al. Synchronous primary ovarian and endometrial cancers: a series of cases and a review of literature. Prz Menopauzalny 2014; 13: 64-69.

16. Marczak A, Denel M. Trabectedin as a single agent and in combination with pegylated liposomal doxorubicin - activity against ovarian cancer cells. Contemp Oncol (Pozn) 2014; 18: 149-152.

17. Deng CY, Tang DM, Yu Q, He FF. Effect of premenopausal hysterectomy on ovarian function. Zhongguo Yi Xue Ke Xue Yuan Xue Bao 2002; 24: 639-642 [Article in Chinese]

18. Petri Nahás EA, Pontes A, Nahas-Neto J, et al. Effect of total abdominal hysterectomy on ovarian blood supply in women of reproductive age. J Ultrasound Med 2005; 24: 169-174.

19. Chalmers C, Lindsay M, Usher D, et al. Hysterectomy and ovarian function: levels of follicle stimulating hormone and incidence of menopausal symptoms are not affected by hysterectomy in women under age 45 years. Climacteric 2002; 5: 366-373.

20. Oldenhave A, Jaszman LJ, Everaer WT, Haspelss A. Hysterectomized women with ovarian conservation report, more severe climacteric complaints than do normal climacteric women of the same age. Am J Gynecol 1993; 168 (3 Pt 1): 765-771.
21. Lemm MA, Skatba P. Biology of ovarian aging. Prz Menopauzalny 2013; 17: 231-234.

22. Bojar I, Witczak M, Stępniak A, et al. Cognitive functions measured with a battery of CNS VS tests and the subjective assessment of memory, concentration impairment and reduction in the quality of life in women after menopause. Prz Menopauzalny 2013; 17: 371-377.

23. Stępniak A, Kot K, Witczak M, et al. Impact of consumption of B-group vitamins on cognitive functions of women after menopause. Prz Menopauzalny 2013; 17: 464-471

24. Ozdamar S, Ulger H, Sorkun HC, Müderris I. Effects of hysterectomy on ovarian morphology and serum FSH level in rats. Maturitas 2005; 52 60-64

25. Tapisiz OL, Gungor T, Aytan H, et al. Does hysterectomy affect ovarian function? Histopathologic evaluation and serum FSH, inhibin A, and in hibin B levels in an experimental rat model. Eur J Obstet Gynecol Reprod Biol 2008; 140: 61-66.

26. Bhattacharya S, Mollison J, Pinion S, et al. A comparison of bladder and ovarian function two years following hysterectomy or endometrial ablation. Br J Obstet Gynaecol 1996; 103: 898-903.

27. Derksen JG, Brölmann HA, Wiegerinck MA, et al. The effect of hysterectomy and endometrial ablation on follicle stimulating hormone (FSH) levels up to 1 year after surgery. Maturitas 1998; 29: 133-138.

28. Korabel J, Krzysiek J. Assessment of the ovarian reserve in a group of perimenopausal women. Prz Menopauzalny 2013; 17: 333-338.

29. Ylikorkala O, Viinikka L. Pituitary and ovarian function in women with congenitally absent uterus. Obstet Gynecol 1979; 53: 137-139.

30. Findley AD, Siedhoff MT, Hobbs KA, et al. Short-term effects of salpingectomy during laparoscopic hysterectomy on ovarian reserve: a pilot randomized controlled trial. Fertil Steril 2003; 100: 1704-1708.

31. Morelli M, Venturella R, Mocciaro R, et al. Prophylactic salpingectomy in premenopausal low-risk women for ovarian cancer: Primum non nocere. Gynecol Oncol 2013; 129: 448-451.

32. Venturella R, Lico D, Sarica A, et al. OvAge: a new methodology to quantify ovarian reserve combining clinical, biochemical and 3D-ultrasonographic parameters. J Ovarian Res 2015; 8: 21.

33. Abdelazim IA, Belal MM, Makhlouf HH. Antimullerian hormone and antral follicle count as predictors of ovarian reserve and successful IVF. Asian Pacific Journal of Reproduction (APJR) 2012; 1: 89-92.

34. Ishii K, Aoki Y, Takakuwa K, Tanaka K. Ovarian function after radical hysterectomy with ovarian preservation for cervical cancer. J Reprod Med 2001; 46: 347-352.

35. Richlin SS, Rock JA. Ovarian remnant syndrome. Gynaecol Endosc 2001; 10: 111-117

36. Zalel Y, Lurie S, Beyth $\mathrm{Y}$, et al. Is it necessary to perform a prophylactic oophorectomy during hysterectomy? Eur J Obstet Gynaecol Reprod Bio 1997; 73: 67-70.

37. Pete I, Bõsze P. The fate of the retained ovaries following radical hysterectomy. Eur J Gynaecol Oncol 1998; 19: 22-24. 